\title{
Short implants versus longer implants with maxillary sinus lift. A systematic review and meta-analysis
}

\section{Ronaldo Silva CRUZ(a) Cleidiel Aparecido de Araújo LEMOS(a) \\ Victor Eduardo de Souza BATISTA ${ }^{(b)}$ \\ Hiskell Francine Fernandes e OLIVEIRA(a) $^{(a)}$ \\ Jéssica Marcela de Luna GOMES(a) \\ Eduardo Piza PELLIZZER(a) \\ Fellippo Ramos VERRI(a)}

(a) Universidade de São Paulo - USP, Aracatuba Dental School, Department of Dental Materials and Prosthodontics, Araçatuba, SP, Brazil.

(b) Universidade do Oeste Paulista - Unoeste, Presidente Prudente Dental School, Department Prosthodontics, Presidente Prudente, SP, Brazil.

Declaration of Interests: The authors certify that they have no commercial or associative interest that represents a conflict of interest in connection with the manuscript.

Corresponding Author:

Ronaldo Silva Cruz

E-mail: ronald_mb@hotmail.com

Submitted: December 12, 2017

Accepted for publication: March 13, 2018

Last revision: July 17, 2018
Abstract: This study compared the survival rate of dental implants, amount of marginal bone loss, and rates of complications (biological and prosthetic) between short implants and long implants placed after maxillary sinus augmentation. This systematic review has been registered at PROSPERO under the number (CRD42017073929). Two reviewers searched the PubMed/MEDLINE, Embase, LILACS, and Cochrane Library databases. Eligibility criteria included randomized controlled trials, comparisons between short implants and long implants placed after maxillary sinus augmentation in the same study, and follow-up for $>6$ months. The Cochrane Collaboration's tool for assessing the risk of bias in randomized trials was used to assess the quality and risk of bias of the included studies. The search identified 1366 references. After applying the inclusion criteria, 11 trials including 420 patients who received 911 dental implants were considered eligible. No significant difference was observed in the survival rate $[p=0.86$; risk ratio (RR): 1.08 ; $95 \%$ confidence interval (CI): 0.46-2.52] or in the amount of marginal bone loss ( $p=0.08$; RR: -0.05 ; $95 \% \mathrm{CI}:-0.10$ to 0.01$)$. However, higher rates of biological complications for long implants associated with maxillary sinus augmentation were observed ( $\mathrm{p}<0.00001$; RR: 0.21; 95\%CI: 0.10-0.41), whereas a higher prosthetic complication rate for short implants was noted $(p=0.010$; RR: 3.15; 95\%CI: 1.32-7.51). Short implant placement is an effective alternative because of fewer biological complications and similar survival and marginal bone loss than long implant placement with maxillary sinus augmentation. However, the risk of mechanical complications associated with the prostheses fitted on short implants should be considered.

Keywords: Dental Implants; Sinus Floor Augmentation; Prosthesis Failures; Meta-Analysis.

\section{Introduction}

Dental implants are considered an option for oral rehabilitation, particularly in the posterior maxillary region. ${ }^{1}$ However, it is not possible to place dental implants with an adequate length in some clinical situations, primarily due to the lack of sufficient bone. ${ }^{2}$ One option to overcome this limitation is using short implants. ${ }^{3}$ Another option is augmentation of the bone height through techniques such as maxillary sinus augmentation with or without bone grafting, which enables long implant placement. ${ }^{4}$ 
Short implant placement has been considered as a less invasive alternative, and it is associated with greater simplicity, a shorter surgical duration, and lower morbidity rates and costs. ${ }^{5,6}$ Furthermore, the clinical outcomes of short implants are reportedly similar to those of long implants in the posterior maxillary region. ${ }^{78}$ However, the bone-to-implant contact area with short implants may be small, impairing the primary stability and osseointegration process $^{9}$ and eventually leading to implant failure. ${ }^{1}$ In addition, the discrepancy in the crown-to-implant ratio (C/I ratio) may increase the risk of marginal bone loss and other complications such as screw loosening, prefabricated abutment fracture, retention loss, and crown debonding. ${ }^{10,11}$ Maxillary sinus augmentation, which is performed using the lateral window technique or Summers technique, has shown favorable outcomes regarding implant survival. ${ }^{6,12}$ However, these are complex surgical procedures because they can result in postoperative complications that increase the morbidity rate and increase the patient's reluctance to undergo the procedure. ${ }^{13,14}$ The cost and duration of treatment are greater than that in conventional implant placement without bone grafting. ${ }^{15}$

Different reviews have reported the use of short implants with available alternative treatments. ${ }^{1,15,16,17}$ However, more randomized controlled trials (RCTs) have reported comparisons between short implants and long implants placed after maxillary sinus augmentation. $8,18,19,20,21,22,23$ Thus, the choice of technique (short or long implants with maxillary sinus augmentation) should be based on recently published literature, including the relative risks of each technique.

The present systematic review aimed to compare short implants and long implants (length $>8.5 \mathrm{~mm}$ ) placed after maxillary sinus augmentation for survival rates, amount of marginal bone loss, and biological and prosthetic complications. The null hypotheses were as follows. First, there is no difference in the survival rate between short implants and long implants placed after maxillary sinus augmentation. Second, the implant length does not influence the amount of marginal bone loss. Third, the implant length does not change the occurrence of biological and/ or prosthetic complications.

\section{Methodology}

This systematic review was registered in the PROSPERO database (CRD42017073929) and structured according to the PRISMA checklist. ${ }^{24}$ The protocol was established according to models proposed in the relevant literature. ${ }^{16,25}$

\section{Eligibility criteria}

Studies meeting the following criteria were included: a. RCTs; b. comparisons between short implants without maxillary sinus augmentation and long implants with maxillary sinus augmentation in the same study; and c. follow-up for $>6$ months. No restrictions on language or date of publication for searching in the electronic databases were made. Studies meeting at least one of the following criteria were excluded: a. animal studies; $b$. in vitro studies; c. case series or case reports; d. retrospective studies; e. patients or data repeated in other articles included; $f$. computer simulations; g. studies that presented only short implants without a comparison group; h. studies that considered short implants longer than $8.5 \mathrm{~mm}$; and i. studies with short implants associated with maxillary sinus augmentation technique.

\section{Search}

The following question was elaborated for the PICO process (population, intervention, comparison, outcomes): Do short posterior maxillary implants exhibit the same clinical predictability as long implants placed after maxillary sinus augmentation? The population $(\mathrm{P})$ was patients rehabilitated with dental implants in the posterior maxilla; the intervention (I) was short implant $(\leq 8.5 \mathrm{~mm})$ placement; the comparison $(\mathrm{C})$ was long implant $(>8.5 \mathrm{~mm}$ ) placement after maxillary sinus augmentation; and the outcomes (O) were the survival rate of implants, amount of marginal bone loss, and biological and prosthetic complication rates.

Two researchers independently searched the PubMed/Medline, Embase, LILACS, and Cochrane Library databases for articles published up to January 2018 according to the eligibility criteria. Studies comparing the survival rate of short implants $(\leq 8.5 \mathrm{~mm})$ placed in the posterior maxilla with that 
of long implants (> $8.5 \mathrm{~mm}$ ) placed after maxillary sinus augmentation were selected. The search terms included (short implant and maxilla) OR (short implant and sinus lift) OR (short implant and sinus elevation) OR (short implant and maxilla and augmentation) OR (short implant and sinus floor augmentation) OR (short implant and maxilla and dental implant) OR (short implant and sinus lift and dental implant) OR (short implant and sinus elevation and dental implant) OR (short implant and maxilla and augmentation and dental implant) OR (short implant and maxilla and dental implant) OR (short implant and sinus floor augmentation and dental implant).

No filters and limits were used in the database searches. A manual search of electronically available publications up to January 2018, including studies available ahead of print, was conducted by two reviewers for specific journals: Clinical Implant Dentistry and Related Research, Clinical Oral Implants Research, International Journal of Oral and Maxillofacial Implants, International Journal of Oral and Maxillofacial Surgery, Journal of Clinical Periodontology, Journal of Dentistry, Journal of Oral and Maxillofacial Surgery, Journal of Oral Implantology, Journal of Oral Rehabilitation, and Journal of Periodontology. A third researcher analyzed the possible differences in the selection of the investigators. Any disagreements were resolved by discussion and consensus of all authors. The Cohen's kappa coefficient was calculated to measure the inter-reader agreement in the study selection process.

\section{Risk of bias}

One author evaluated the risk of bias in the included studies using the Cochrane Collaboration's tool for assessing the risk of bias in randomized trials. The assessment criteria were separately prepared for different domains: random sequence generation, allocation concealment, blinding (patients and/or outcome assessment), incomplete outcome data, and other bias. For each domain, the risk of bias was graded as high, low, or unclear based on criteria described in the Cochrane Handbook for Systematic Reviews of Interventions version 5.1.0. A second author was responsible for checking the risk of bias, and a consensus was obtained with another author in case of discrepancies.

\section{Data extraction}

One researcher extracted the data from articles (quantitative or qualitative), and another check these data. The following data were recorded: author/year, number of patients, mean age, length of short and long implants and number of implants, diameter $(\mathrm{mm})$ of implants, implant system, insertion bone graft/system, technique performed, follow-up (months), amount of marginal bone loss, complications (biological and prosthetic), and survival rates of implants (short and long implants).

\section{Summary measures}

The meta-analysis was based on the MantelHaenszel (MH) and Inverse Variance (IV) weighting methods. The outcome measures evaluated by risk ratio (RR) included the survival rates of implants and biological and prosthetic complications. The amount of marginal bone loss was evaluated by mean difference (MD) and the corresponding 95\% confidence interval (CI). The RR and MD values were considered significant when the P-value was $<0.05$. Reviewer Manager 5 software (the Cochrane Collaboration) was used for meta-analysis. The $\mathrm{I}^{2}$ statistic was used to analyze the percentage of variations due to heterogeneity. $\mathrm{I}^{2}$ values > 75\% (range: $0-100)$ indicated high heterogeneity. Because the meta-analysis showed significant heterogeneity $(\mathrm{p}<$ 0.10 ), a random-effects model was adopted, whereas the fixed-effect model was used when heterogeneity was not statistically significant. $26,27,28$

\section{Results}

The database search yielded 1366 references, including 421 from PubMed/MEDLINE, 414 from Embase, 453 from LILACS, and 78 from Cochrane Library. Following the selection of studies according to the inclusion and exclusion criteria and the removal of duplicate articles, full versions of 26 articles were selected for reading (Figure 1). After reading, 11 studies $8,18,19,20,21,22,23,29,30,31,32$ met the inclusion criteria and were selected for the final analysis. Thus, 15 studies were excluded $^{4,5,6,7,33,34,35,36,37,38,39,40,41,42,43}$; the reasons for exclusion are specified in Table 1. 


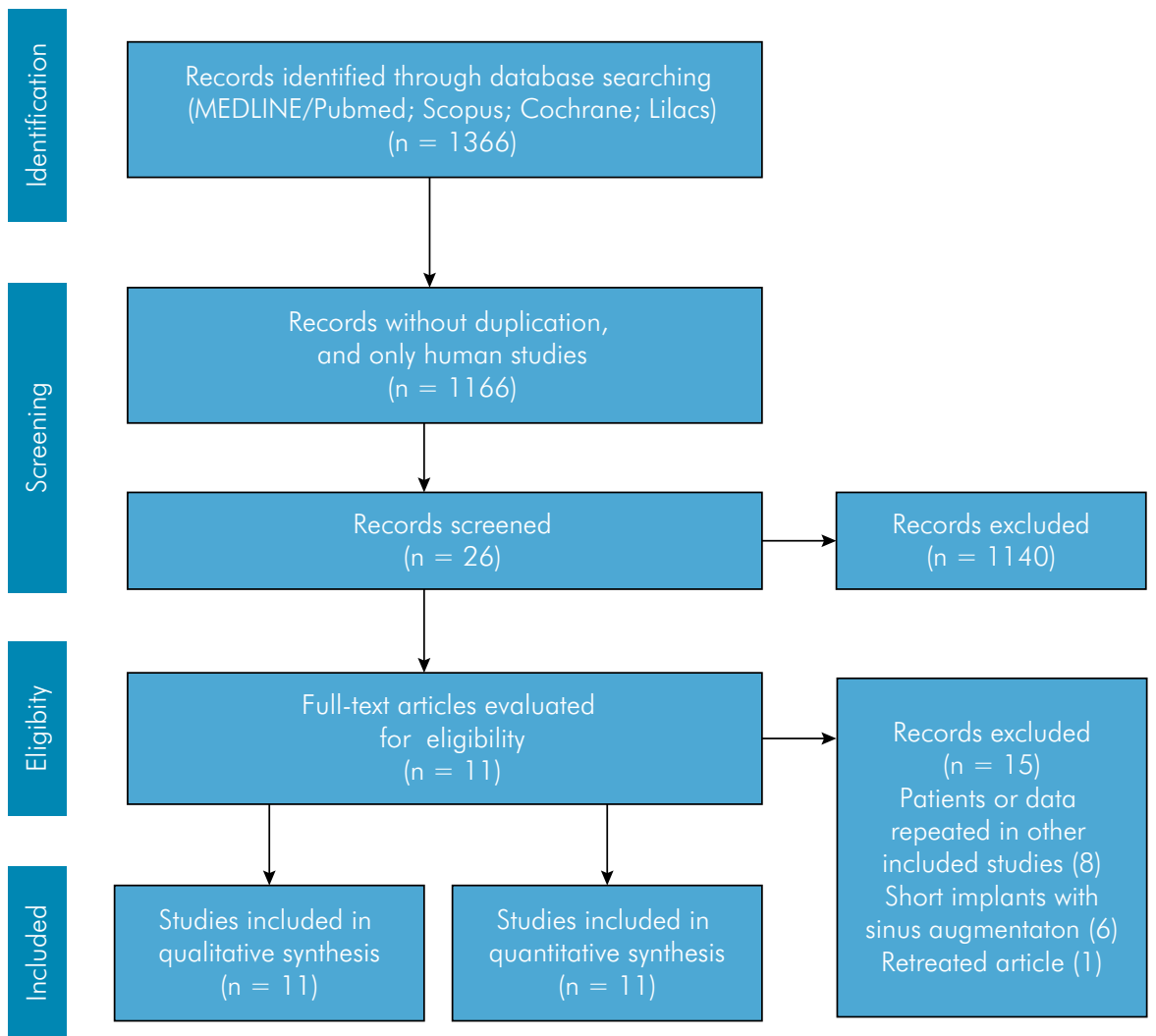

Figure 1. Flow diagram of the literature search and results

Table 1. Reasons for the exclusion of 15 articles.

\begin{tabular}{lc}
\hline Reason for Exclusion & References \\
\hline Patients or data repeated in other included articles & $5,6,33,34$, \\
$35,36,37,38$ \\
Short implants with sinus augmentation & $4,7,39,40$, \\
41,42 \\
Retread & 43
\end{tabular}

The inter-investigator agreement (Kappa) was calculated by evaluating the selected titles and abstracts. The values derived for the articles selected from PubMed/MEDLINE (kappa = 0.96), Embase (kappa $=0.95)$, LILACS (kappa $=0.93)$, and Cochrane Library (kappa $=1.00)$ suggested a high level of agreement between investigators.

A total of 420 patients with a mean age of 52.20 years received 911 implants, including 437 shortimplants and 474 long implants placed after maxillary sinus augmentation; the implants were performed using the following techniques: osteotome sinus floor elevation, ${ }^{18}$ crestal sinus lift, ${ }^{21}$ and lateral sinus lift. ${ }^{8,192,2,22,23,29,30,31,32}$ The lateral sinus augmentation procedure was performed with bone grafting in all studies, ${ }^{8,19,20,22,23,29,30,31,32}$ with xenografts being most commonly used. One study used an autograft (iliac crest donor site), ${ }^{23}$ and another did not use any graft materials. ${ }^{18}$ The commercially available implant systems included those produced by BTI Biotechnology Institute (Vitoria, Alava, Spain), Zimmer Biomet (Palm Beach Gardens, FL, USA), Institut Straumann AG (Basel, Switzerland), Dentsply Implants (Molndal, Sweden), MegaGen (Gyeongbuk, South Korea), Global D (Lyon, France), and Southern Implants (Irene, South Africa).

The length of short implants ranged from 4 $\mathrm{mm}$ to $8.5 \mathrm{~mm}$, while that of conventional, long implants ranged from $10 \mathrm{~mm}$ to $15 \mathrm{~mm}$. The diameter of all implants ranged from $3.75 \mathrm{~mm}$ to $7.0 \mathrm{~mm}$. In addition, five studies reported the use of internal connections, ${ }^{8,19,20,22,29}$ four used external connections, ${ }^{21,23,31,32}$ and two did not report the type of connection..$^{18,30}$ The follow-up period of included studies varied from 9 to 36 months (Table 2). 


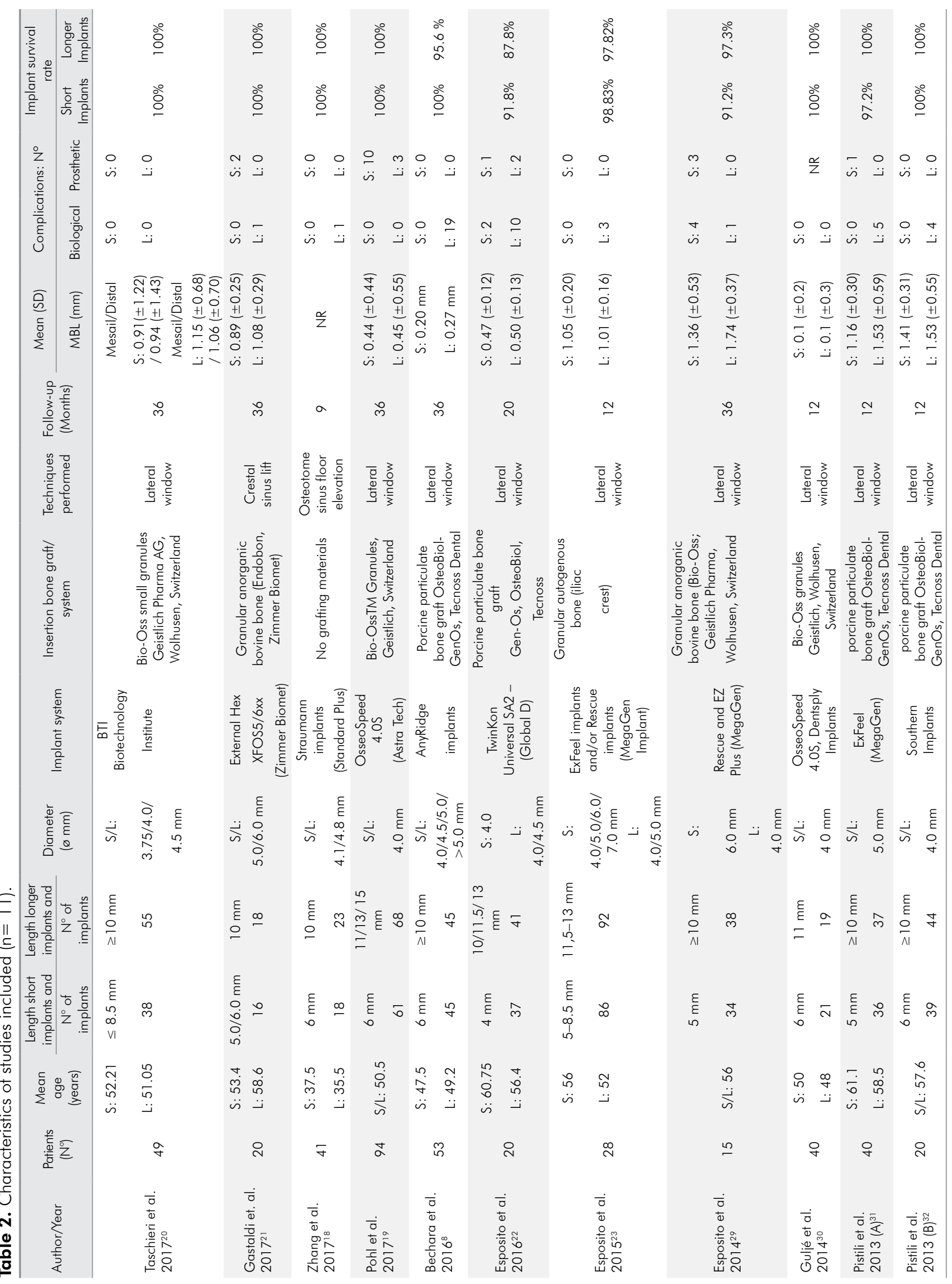




\section{Risk of bias}

The Cochrane Collaboration's tool for assessing risk of bias in randomized trials indicated that all studies showed a low risk of bias for random sequence generation, allocation concealment (selection bias), incomplete outcome data (attrition bias), selective reporting (reporting bias), and other sources of bias. Regarding blinding of participants and personnel, one study reported the blinding of patients without the blinding of surgeons ${ }^{18}$ whereas two studies reported no blinding of surgeons. ${ }^{31,32}$ All other studies were unclear about this parameter. This may have been due to difficulty in blinding surgeons and/or patients scheduled for auxiliary surgical, particularly in split-mouth design studies. ${ }^{29,31,32}$ Blinding of outcome assessment was reported for almost all included studies. ${ }^{18,21,22,23,29,31,32}$ However, a few studies were unclear regarding this. ${ }^{8,20,30}$ (Figure 2).

\section{Implant survival rate}

All the studies included the cumulative implant survival rate. Among the 911 dental implants placed in the posterior maxilla, , 8,18,19,20,21,22,23,29,30,31,32 only 18 (1.97\%) failed. These included nine short implants $(2.05 \%)$ and nine long implants placed after maxillary sinus augmentation (1.89\%). Twelve implants were lost before loading (six short implants and six long implants). After loading, six implants were lost (three short implants and three long implants).
Among the reported lost implants, eight studies used a regular diameter, ${ }^{8,18,19,20,22,23,30,32}$ and five studies used a wide diameter ${ }^{8,21,23,29,31}$ for short implants, whereas nine studies used a regular diameter $8,18,19,20,22,23,29,30,32$ and four studies used a wide diameter ${ }^{8,21,23,31}$ for long implants placed after sinus augmentation. The studies reported different reasons for implant failures, such as smoking habits and periodontal disease, ${ }^{8}$ mobility at implant-abutment connection, ${ }^{22,23}$ problems with the osseointegration process, and overload caused by prostheses. ${ }^{23}$ The results of the meta-analysis verified no difference in the survival rate between short implants and long implants placed after maxillary sinus augmentation ( $p=0.86$; RR: 1.08; 95\%CI: 0.46-2.52) (Figure 3).

\section{Marginal bone loss}

Ten studies reported data in terms of the amount of marginal bone loss, which was reported in millimeters. However, only eight of these studies ${ }^{19,21,22,23,29,30,31,32}$ were used for meta-analysis because one study reported bone loss separately (mesial and distal), ${ }^{20}$ and another study reported marginal bone loss without standard deviation. ${ }^{8}$ The mean amount of marginal bone loss for short implants was $0.86 \mathrm{~mm}$ (range: $0.10-1.41 \mathrm{~mm}$ ), whereas for long implants placed after maxillary sinus augmentation, it was $0.99 \mathrm{~mm}$ (range: $0.10-1.74 \mathrm{~mm}$ ). The meta-analysis based on MD found no significant difference between short implants and long implants ( $\mathrm{p}=0.08$; RR: $-0.05 ; 95 \% \mathrm{CI}:-0.10$ to 0.01$)$ (Figure 4$)$.

Random sequence generation (selection bias)

Allocation concealment (selection bias)

Blinding of participants and personnel (performance bias)

Blinding of outcome assessment (detection bias)

Incomplete outcome data (attrition bias)

Selective reporting (reporting bias)

Other bias
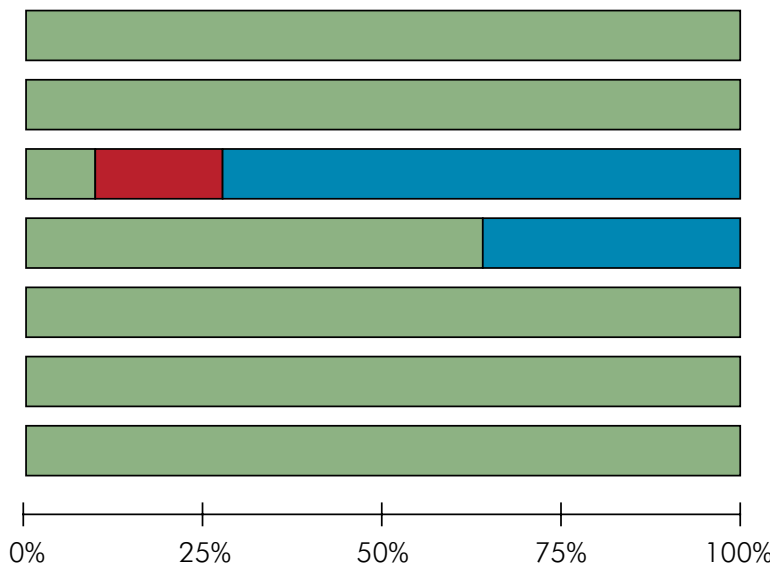

Low risk of bias

Unclear risk of bias

High risk of bias

Figure 2. Included studies assessed using Cochrane Collaboration's tool for assessing risk of bias in randomized trials 


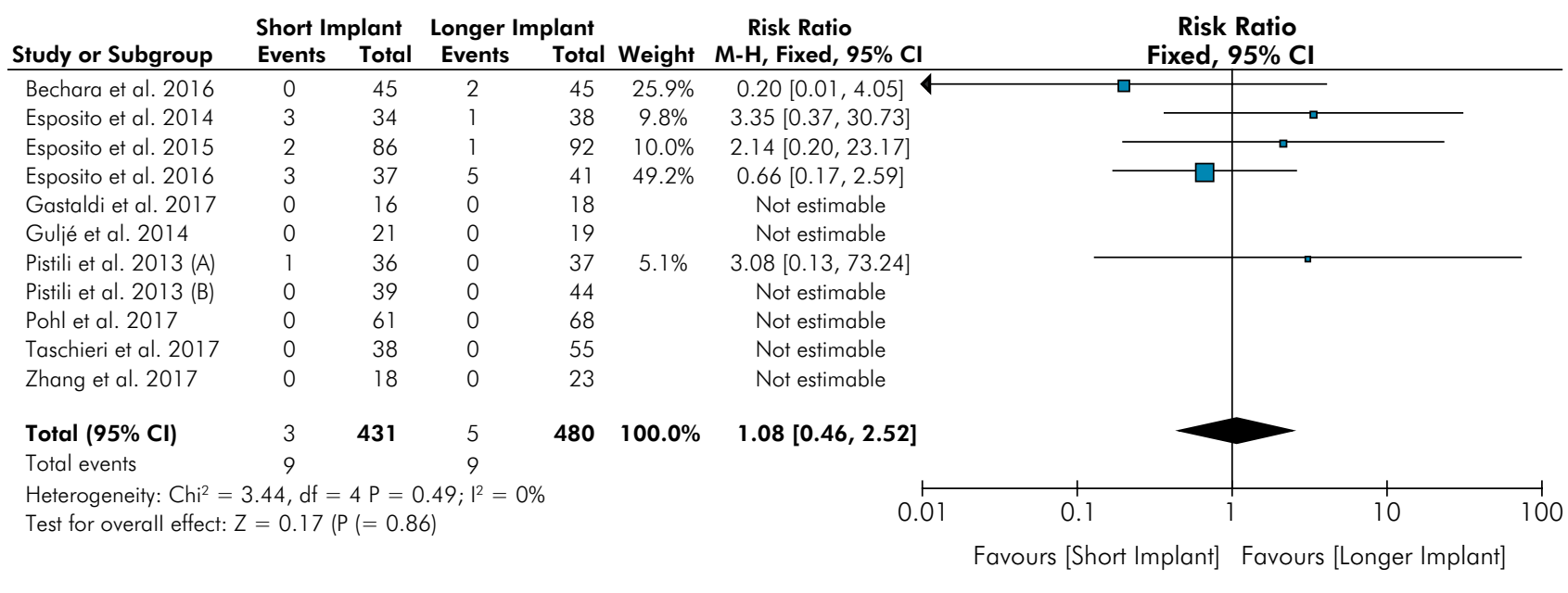

Figure 3. Forest plot for the event "implant survival"

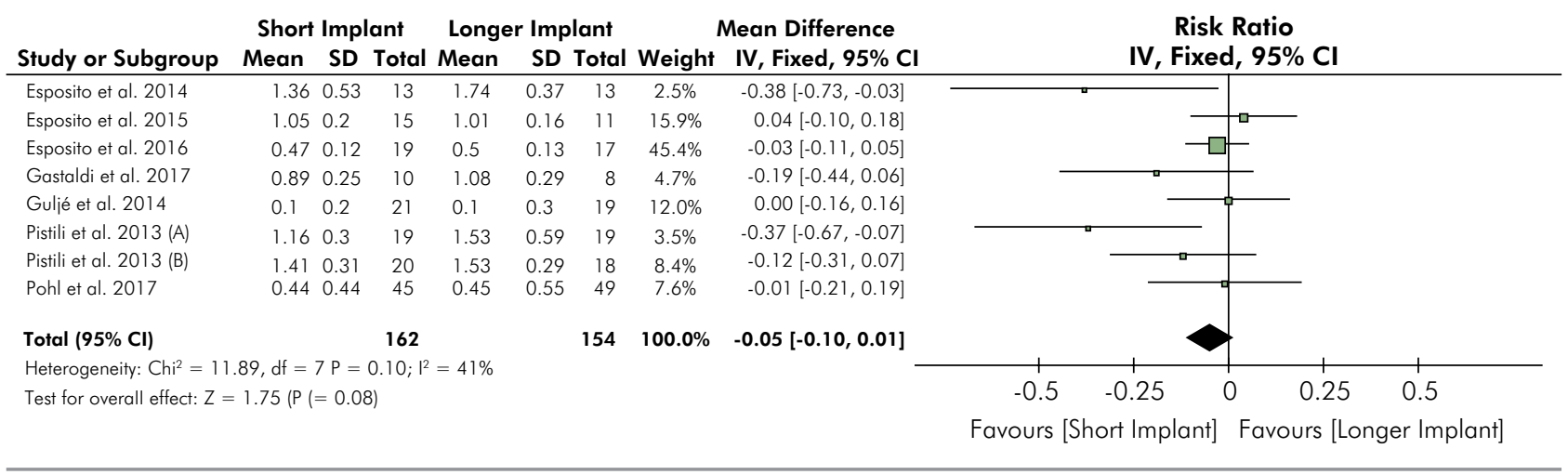

Figure 4. Forest plot for the event "marginal bone loss"

\section{Biological complications}

Biological complications were reported in eight included studies; $;, 18,21,22,23,29,31,32$ however, three studies did not verify any biological complications after the follow-up period. ${ }^{19,20,30}$ There were immediate postoperative complications (pain and swelling after surgery, acute sinus infection) as well as late postoperative complications (chronic sinus infection, partial or total graft failure). Short implants were associated with significantly lower biological complication rates compared with long implants placed after maxillary sinus augmentation $(\mathrm{p}<0.00001$; RR: 0.21; 95\%CI: 0.10-0.41) (Figure 5). The most common complications associated with long implants included perforated sinus membrane, palpation pain, pain and swelling after surgery, chronic sinus infection, and postoperative bleeding. ${ }^{8,21,22,23,29,32}$

\section{Prosthetic complications}

Ten studies reported data for prosthetic complications; $;, 18,19,20,21,22,23,29,31,32$ however, five studies did not verify the type of prosthetic complications after the follow-up period $8,18,20,23,32$ The reported complications included fracture of the metal structures in the restoration, ceramic fractures, debonding, retention loss, abutment fracture, and fixation screw loosening. ${ }^{19,21,22,29,31}$ Short implants were associated with higher rates of prosthetic complications compared with long implants ( $p=0.010$; RR: 3.15; 95\%p CI: 1.32-7.51) (Figure 6).

\section{Heterogeneity}

Heterogeneity was considered low for the survival rates of implants $\left(\mathrm{P}=0.49 ; \mathrm{I}^{2}=0 \%\right)$, amount of marginal bone loss $\left(\mathrm{p}=0.10 ; \mathrm{I}^{2}=41 \%\right)$, biological complications 


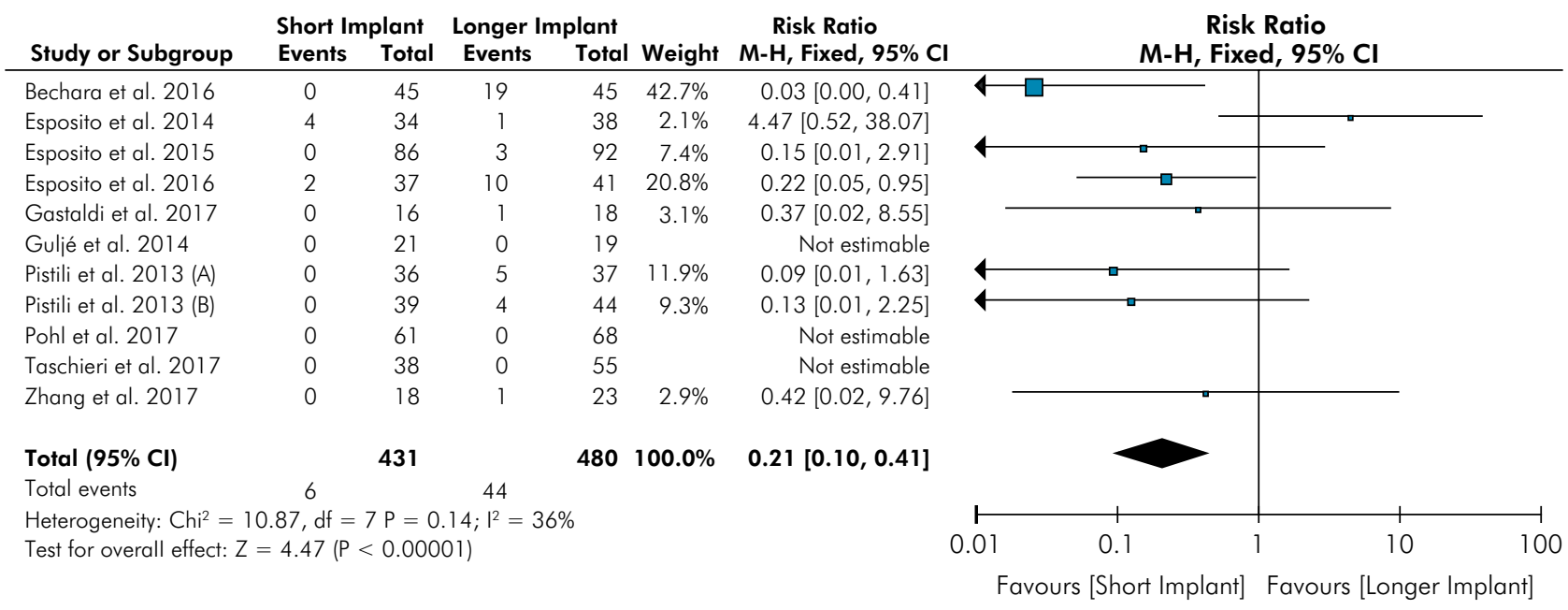

Figure 5. Forest plot for the event "biological complications"

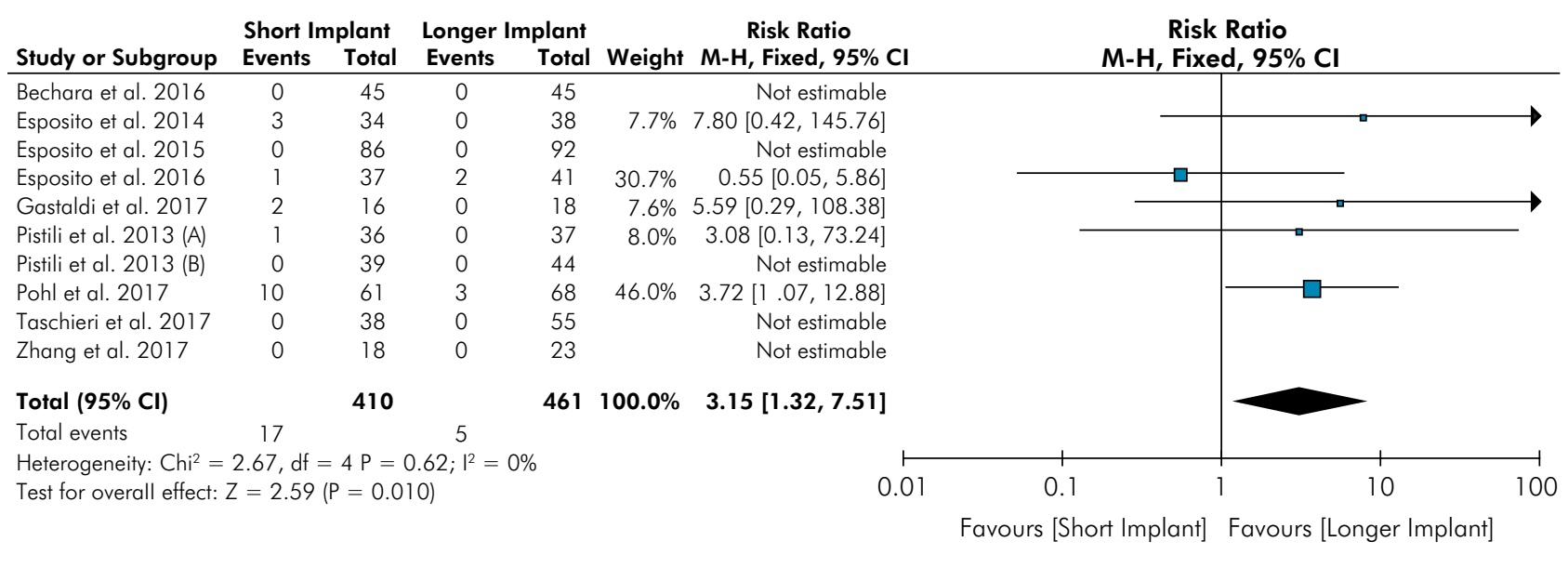

Figure 6. Forest plot for the event "prosthetic complications"

$\left(\mathrm{p}=0.14 ; \mathrm{I}^{2}=36 \%\right)$, and prosthetic complications $\left(p=0.62 ; I^{2}=0 \%\right)$. Furthermore, the funnel plots did not show asymmetry for all analyses, indicating the absence of publication bias (Figure 7).

\section{Discussion}

The findings of this systematic review and metaanalysis suggested that for posterior maxillary rehabilitation, short and long implant placement have similar implant survival rates. Thus, the first null hypothesis was accepted. Moreover, this finding agrees with the findings in studies reporting high success rates for short implants used for posterior maxillary rehabilitation. ${ }^{1,8,18,44}$ Furthermore, different systematic reviews evaluating only short implants showed survival rates between $93.1 \%$ and $99.1 \%, 45,46$ which corroborate with the survival rate of $98.09 \%$ in the current review.

Among the selected studies, only five reported information pertaining to implant loss, including nine short implants and nine long implants. Accordingly, the failure rates for short and long implants were $1.90 \%$ and $1.95 \%$, respectively. Some studies have reported mobility, chronic sinus infection, and history of periodontal disease and abscess as reasons for implant 
A

B
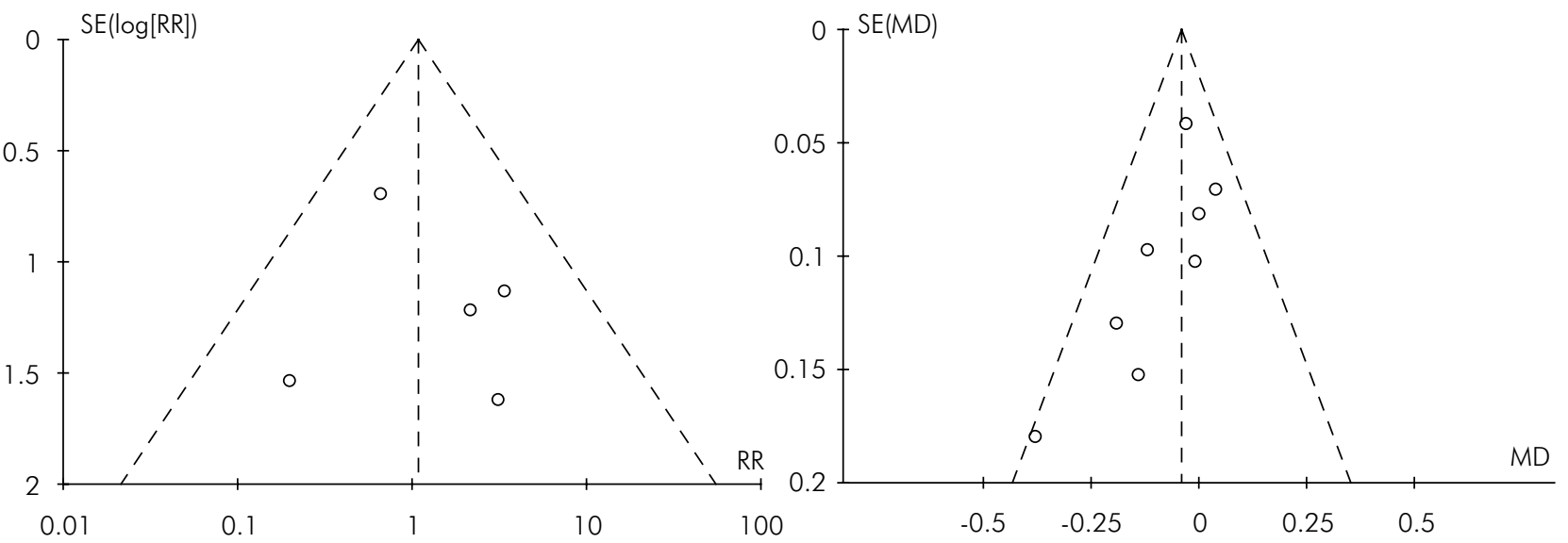

C

D
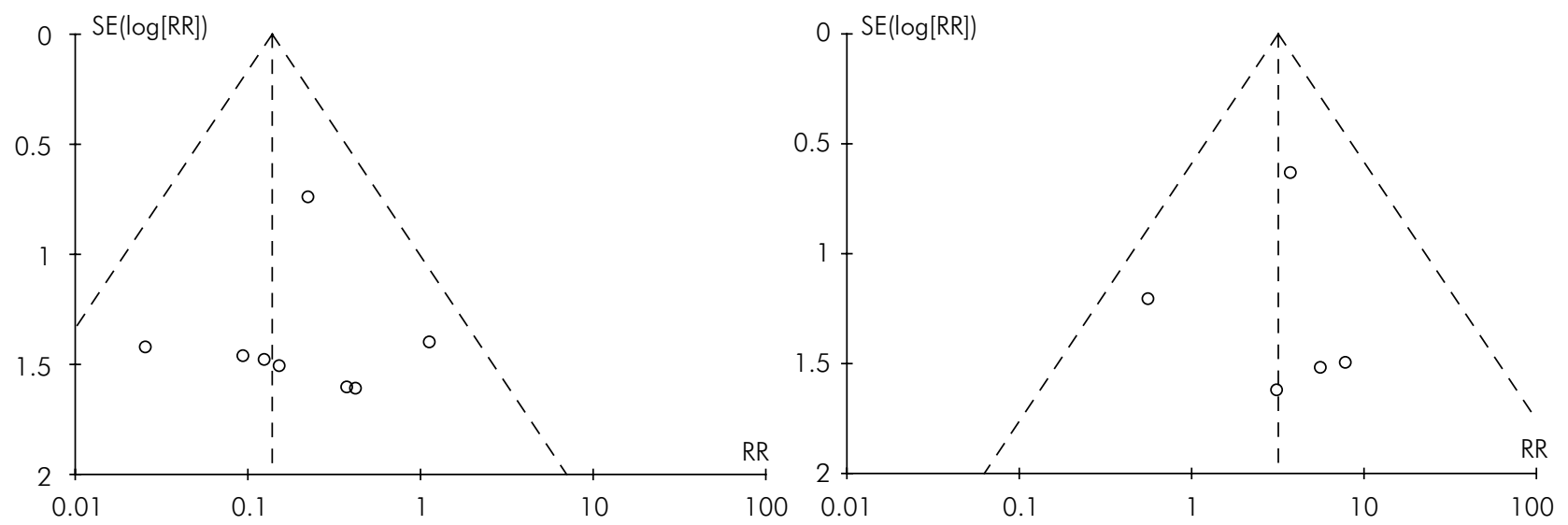

Figure 7. Funnel plot for the assessment of publication bias for A, "implant survival," B, "marginal bone loss," C, "biological complications," and D, "prosthetic complications"

loss. $8,22,23,29$ However, not all studies have reported the reasons for implant loss ${ }^{31}$. Some risk factors may influence the survival of implants, ${ }^{47,48,49}$ including occlusal overload after prosthetic rehabilitation. From the biomechanical perspective, when comparing short implants with long implants, short implants may be associated with a trend for higher stresses within the implant and consequently on the cortical bone tissue. ${ }^{50}$ However, this can be overcome by using implants with splinted crowns. . $^{50,51}$

Another factor that may influence the increase in implant survival rate, regardless of length and diameter, is the fact that some studies report that implants with a wide diameter $(\geq 5 \mathrm{~mm}$ ) are more favorable than implants with a narrow and regular diameter. ${ }^{52,53}$ No such association was found in the present systematic review and meta-analysis. Studies that used implants with a 4-mm diameter showed 100\% survival rates for both types of implants. ${ }^{19,30,32}$ Similarly, studies that analyzed implants with a diameter of 5 $\mathrm{mm}$ reported survival rates of $100 \%$ for long implants placed after maxillary sinus augmentation and 97.2\% for short implants. ${ }^{31}$ The reason for this finding may be consideration of the implant diameter as a secondary factor for the long-term survival of implants placed in the posterior maxillary region. ${ }^{54}$

Primary stability is also essential for the success of dental implants. ${ }^{49,55}$ A lack of primary stability may compromise osseointegration and the longevity of osseointegrated implants. ${ }^{56,57}$ Analysis of the implant 
stability quotient (ISQ) using devices such as the Osstell ISQ has been documented in only two studies, ${ }^{8,18}$ which stated high values indicating good primary stability after both short and long implant placement. Resonance frequency analysis measurements result in a mean ISQ value of 68.68 for short implants and 70.69 for long implants placed after sinus augmentation. These findings are consistent with those of a previous study reporting the achievement of good primary stability for short implants. ${ }^{58}$ Furthermore, these values are within the limits previously established in the literature (54-74 ISQ). ${ }^{59}$

The literature suggests that modification of the implant design and surface may accelerate the process of osseointegration and influence the success of dental implants, ${ }^{60}$ primarily in the analysis of short implants and machined implants. ${ }^{47,49}$ The surface properties of the implant have been identified as an important factor for osseointegration. ${ }^{61,62}$ Bechara et al. ${ }^{8}$ performed a unique study that assessed implant surfaces reinforced with nanostructured calcium and reported a high success rate for both long implants placed after maxillary sinus augmentation (95.6\%) and short implants (100\%); however, the study did not perform comparisons with other surfaces. Therefore, it is difficult to conclude whether there is an actual benefit in terms of the success rate, particularly for short implants.

Marginal bone stability is another relevant factor for implant-supported rehabilitation because excess bone loss is considered as one of the secondary factors that may lead to implant loss ${ }^{63}$ However, the current analysis finds no difference in the marginal bone loss between short implants and long implants placed after maxillary sinus augmentation. Thus, the second hypothesis was also accepted. Moreover, this finding is consistent with previous data showing similarity in marginal bone loss values for short and long implants placed in the posterior jaw. ${ }^{1}$

Although there was no difference in marginal bone loss in the present systematic review, it is important to note that several studies observed greater marginal bone loss with long implants placed after maxillary sinus augmentation..$^{8,21,29,31,32}$ This bone loss may have occurred because long implants are supported on grafted bone, which is considered to be of poorer quality compared with natural bone. ${ }^{64}$ In this way, it is indicated that the use of short implant is preferable considering only the bone loss aspect. However, no difference for bone loss between implant lengths was observed in this study. In addition, prosthetic complications are statistically more common for long implants and preclude a simple explanation. It is important to emphasize that bone loss may be influenced by several factors such as the implant geometry, ${ }^{65}$ parafunctional habits, ${ }^{66}$ crown fixation system, ${ }^{67}$ biological factors, ${ }^{68}$ systemic factors ${ }^{63}$ overheating during surgical preparation, ${ }^{44,47}$ and the prosthesis loading condition. ${ }^{25}$ However, because of lack of data in the included studies, we could not perform sub-analyses based on these variables, and this may be considered as a limitation to our study.

The third hypothesis was rejected because significant differences were found in the biological and prosthetic complication rates between short implants and long implants placed after maxillary sinus augmentation. In the quantitative analysis of biological complications, a higher rate for long implants than for short implants was seen, which is consistent with previous findings showing an increased risk of biological complications after the performance of complementary surgical procedures for bone augmentation. ${ }^{44,69}$

The use of auxiliary techniques such as maxillary sinus augmentation is less accepted than conventional implant placement techniques because it results in increased morbidity, costs, and surgical duration ${ }^{35,70}$ along with an increase in the time required for rehabilitation. ${ }^{35}$ The main complications reported in the included studies were membrane perforation, bleeding and sinusitis, $8,18,22,29,31,32$ and pain and swelling ${ }^{-8,22,23}$ However, these factors, even if documented as complications, cannot be considered limiting in terms of the decision to perform maxillary sinus augmentation for long implant placement, particularly if the dental surgeon has a good learning curve.

Regarding the rate of prosthetic complications, short implants are considered unfavorable compared with long implants. These results are in agreement with those reported in the literature, which indicate higher risks of prosthetic complications with the use of short implants because of an increase in the C/I 
ratio, which leads to mechanical failures such as loosening, pillar bolt, and ceramic fractures. $19,22,29,31,71,72$ Verri et al. ${ }^{73}$ reported that a C/I ratio of 1:1 may be considered more favorable in terms of lowering the risk of mechanical or prosthetic complications.

The results of the present review must be evaluated with care due to the limitations presented in the selected studies. One limitation of our review is the short follow-up period in some included studies and the small sample size in others. Moreover, some selected studies did not report failure rates for the different variables such as diameter, implantabutment connection, C/I ratio, and others. Finally, in some studies, the length of the implants was selected by the surgeon according to individual

\section{References}

1. Lemos CA, Ferro-Alves ML, Okamoto R, Mendonça MR, Pellizzer EP. Short dental implants versus standard dental implants placed in the posterior jaws: A systematic review and meta-analysis. J Dent. 2016 Apr;47:8-17. https://doi.org/10.1016/i.jdent.2016.01.005

2. Chan HL, Suarez F, Monje A, Benavides E, Wang HL. Evaluation of maxillary sinus width on cone-beam computed tomography for sinus augmentation and new sinus classification based on sinus width. Clin Oral Implants Res. 2014 Jun;25(6):647-52. https://doi.org/10.1111/clr.12055

3. Esfahrood ZR, Ahmadi L, Karami E, Asghari S. Short dental implants in the posterior maxilla: a review of the literature. $J$ Korean Assoc Oral Maxillofac Surg. 2017 Apr;43(2):70-6. https://doi.org/10.5125/jkaoms.2017.43.2.70

4. Yu H, Wang X, Qiu L. Outcomes of 6.5-mm Hydrophilic Implants and Long Implants Placed with Lateral Sinus Floor Elevation in the Atrophic Posterior Maxilla: A Prospective, Randomized Controlled Clinical Comparison. Clin Implant Dent Relat Res. 2017 Feb;19(1):111-22. https://doi.org/10.1111/cid.12439

5. Cannizzaro G, Felice P, Leone M, Viola P, Esposito M. Early loading of implants in the atrophic posterior maxilla: lateral sinus lift with autogenous bone and Bio-Oss versus crestal mini sinus lift and 8-mm hydroxyapatite-coated implants: a randomised controlled clinical trial. Eur J Oral Implantol. 2009;2(1):25-38

6. Felice P, Soardi E, Pellegrino G, Pistilli R, Marchetti C, Gessaroli $M$ et al. Treatment of the atrophic edentulous maxilla: short implants versus bone augmentation for placing longer implants: five-month post-loading results of a pilot randomised controlled trial. Eur J Oral Implantol. 2011;4(3):191-202. clinical circumstances. Further RCTs that include parameters that may influence the findings such as $\mathrm{C} / \mathrm{I}$ ratio, splinting factor, implant geometry, and implant surface, should be conducted.

\section{Conclusion}

In conclusion, our findings suggest that short implant placement is an effective alternative to long implant placement with maxillary sinus augmentation because of fewer biological complications and similar survival and marginal bone loss. However, the risk of mechanical complications associated with the prostheses fitted on short implants should be considered.

7. Cannizzaro G, Felice P, Minciarelli AF, Leone M, Viola P, Esposito M. Early implant loading in the atrophic posterior maxilla: 1-stage lateral versus crestal sinus lift and $8 \mathrm{~mm}$ hydroxyapatite-coated implants: a 5-year randomised controlled trial. Eur J Oral Implantol. 2013;6(1):13-25.

8. Bechara S, Kubilius R, Veronesi G, Pires JT, Shibli JA, Mangano FG. Short (6-mm) dental implants versus sinus floor elevation and placement of longer ( $\geq 10-\mathrm{mm}$ ) dental implants: a randomized controlled trial with a 3-year followup. Clin Oral Implants Res. 2017 Sep;28(9):1097-107. https://doi.org/10.1111/clr.12923

9. Al-Hashedi AA, Taiyeb Ali TB, Yunus N. Short dental implants: an emerging concept in implant treatment. Quintessence Int. 2014 Jun;45(6):499-514. https://doi.org/10.3290/i.qi.a31539

10. Mangano F, Macchi A, Caprioglio A, Sammons RL, Piattelli A, Mangano C. Survival and complication rates of fixed restorations supported by locking-taper implants: a prospective study with 1 to 10 years of follow-up. J Prosthodont. 2014 Aug;23(6):434-44. https://doi.org/10.1111/jopr.12152

11. Ramos Verri F, Santiago Junior JF, Almeida DAF, Oliveira GB, Batista VES, Honório HM et al. Biomechanical influence of crown-to-implant ratio on stress distribution over internal hexagon short implant: 3-D finite element analysis with statistical test. J Biomech. 2015 Jan;48(1):138-45. https://doi.org/10.1016/i.jbiomech.2014.10.021

12. Papaspyridakos P, Ostuni A, Han C, Lal K. Posterior maxillary segmental osteotomy for the implant reconstruction of a vertically deficient ridge: a 3-year clinical report. J Prosthet Dent. 2013 Aug;110(2):69-75. https://doi.org/10.1016/S0022-3913(13)00137-6 
13. Del Fabbro M, Testori T, Francetti L, Weinstein R. Systematic review of survival rates for implants placed in the grafted maxillary sinus. Int J Periodontics Restorative Dent. 2004 Dec;24(6):565-77.

14. Esposito M, Cannizarro G, Soardi E, Pellegrino G, Pistilli $R$, Felice P. A 3-year post-loading report of a randomised controlled trial on the rehabilitation of posterior atrophic mandibles: short implants or longer implants in vertically augmented bone? Eur J Oral Implantol. 2011;4(4):301-11.

15. Esposito M, Felice P, Worthington HV. Interventions for replacing missing teeth: augmentation procedures of the maxillary sinus. Cochrane Database Syst Rev. 2014 May;(5):CD008397. https://doi.org/10.1002/14651858.CD008397.pub2

16. Gonçalves TM, Bortolini S, Martinolli M, Alfenas BF, Peruzzo DC, Natali A et al. Long-term Short Implants Performance: Systematic Review and Meta-Analysis of the Essential Assessment Parameters. Braz Dent J. 2015 Jul-Aug;26(4):325-36. https://doi.org/10.1590/0103-6440201300265

17. Nisand D, Picard N, Rocchietta I. Short implants compared to implants in vertically augmented bone: a systematic review. Clin Oral Implants Res. 2015 Sep;26 Suppl 11:170-9. https://doi.org/10.1111/clr.12632

18. Zhang XM, Shi JY, Gu YX, Qiao SC, Mo JJ, Lai HC. Clinical Investigation and Patient Satisfaction of Short Implants Versus Longer Implants with Osteotome Sinus Floor Elevation in Atrophic Posterior Maxillae: A Pilot Randomized Trial. Clin Implant Dent Relat Res. 2017 Feb;19(1):161-6. https://doi.org/10.1111/cid.12435

19. Pohl V, Thoma DS, Sporniak-Tutak K, Garcia-Garcia A, Taylor TD, Haas R et al. Short dental implants $(6 \mathrm{~mm})$ versus long dental implants (11-15 mm) in combination with sinus floor elevation procedures: 3-year results from a multicentre, randomized, controlled clinical trial. J Clin Periodontol. 2017 Apr;44(4):438-45. https://doi.org/10.1111/jcpe.12694

20. Taschieri S, Lolato A, Testori T, Francetti L, Del Fabbro M. Short dental implants as compared to maxillary sinus augmentation procedure for the rehabilitation of edentulous posterior maxilla: three-year results of a randomized clinical study. Clin Implant Dent Relat Res. 2018 Feb;20(1):9-20. https://doi.org/10.1111/cid.12563

21. Gastaldi G, Felice P, Pistilli R, Barausse C, Trullenque-Eriksson A, Esposito M. Short implants as an alternative to crestal sinus lift: a 3-year multicentre randomised controlled trial. Eur J Oral Implantol. 2017;10(4):391-400.

22. Esposito M, Zucchelli G, Barausse C, Pistilli R, TrullenqueEriksson A, Felice P. Four mm-long versus longer implants in augmented bone in atrophic posterior jaws: 4 -month postloading results from a multicentre randomised controlled trial. Eur J Oral Implantol. 2016;9(4):393-409.

23. Esposito M, Barausse C, Pistilli R, Sammartino G, Grandi G, Felice $P$. Short implants versus bone augmentation for placing longer implants in atrophic maxillae: one-year post-loading results of a pilot randomised controlled trial. Eur J Oral Implantol. 2015;8(3):257-68.
24. Moher D, Liberati A, Tetzlaff J, Altman DG. Preferred reporting items for systematic reviews and meta-analyses: the PRISMA statement. Int J Surg. 2010;8(5):336-41. https://doi.org/10.1016/j.ijsu.2010.02.007

25. Mello CC, Lemos CA, Verri FR, Dos Santos DM, Goiato MC, Pellizzer EP. Immediate implant placement into fresh extraction sockets versus delayed implants into healed sockets: A systematic review and meta-analysis. Int J Oral Maxillofac Surg. 2017 Sep;46(9):1162-77. https://doi.org/10.1016/j.ijom.2017.03.016

26. Medeiros FCFL, Kudo GAH, Leme BG, Saraiva PP, Verri FR, Honório HM et al. Dental implants in patients with osteoporosis: a systematic review with meta-analysis. Int J Oral Maxillofac Surg. 2018 Apr;47(4):480-491. https://doi.org/10.1016/j.ijom.2017.05.021

27. Chrcanovic BR, Albrektsson T, Wennerberg A. Immediately loaded non-submerged versus delayed loaded submerged dental implants: a meta-analysis. Int J Oral Maxillofac Surg. 2015 Apr;44(4):493-506. https://doi.org/10.1016/i.ijom.2014.11.011

28. Egger M, Smith GD. Principles of and procedures for systematic reviews. In: Egger M, Smith GD, Altman DG, editors. Systematic reviews in health care: meta-analysis in context. London: BMJ Books; 2003. p. 23-42.

29. Esposito M, Pistilli R, Barausse C, Felice P. Three-year results from a randomised controlled trial comparing prostheses supported by $5-\mathrm{mm}$ long implants or by longer implants in augmented bone in posterior atrophic edentulous jaws. Eur J Oral Implantol. 2014;7(4):383-95.

30. Guljé FL, Raghoebar GM, Vissink A, Meijer HJ. Single crowns in the resorbed posterior maxilla supported by either $6-\mathrm{mm}$ implants or by $11-\mathrm{mm}$ implants combined with sinus floor elevation surgery: a 1-year randomized controlled trial. Eur J Oral Implantology. 2014;7(3):247-55.

31. Pistilli R, Felice P, Piattelli M, Gessaroli M, Soardi E, Barausse $\mathrm{C}$ et al. Posterior atrophic jaws rehabilitated with prostheses supported by $5 \times 5 \mathrm{~mm}$ implants with a novel nanostructured calcium-incorporated titanium surface or by longer implants in augmented bone: one-year results from a randomised controlled trial. Eur J Oral Implantol. 2013;6(4):343-57.

32. Pistilli R, Felice P, Cannizzaro G, Piatelli M, Corvino V, Barausse C et al. Posterior atrophic jaws rehabilitated with prostheses supported by $6 \mathrm{~mm}$ long $4 \mathrm{~mm}$ wide implants or by longer implants in augmented bone: one-year post-loading results from a pilot randomised controlled trial. Eur J Oral Implantol. 2013;6(4):359-72.

33. Felice P, Pistilli R, Barausse C, Bruno V, Trullenque-Eriksson A, Esposito M. Short implants as an alternative to crestal sinus lift: A 1-year multicentre randomised controlled trial. Eur J Oral Implantol. 2015;8(4):375-84.

34. Schincaglia GP, Thoma DS, Haas R, Tutak M, Garcia A, Taylor TD et al. Randomized controlled multicenter study comparing short dental implants $(6 \mathrm{~mm})$ versus longer dental implants $(11-15 \mathrm{~mm})$ in combination with sinus floor elevation procedures. Part 2: clinical and radiographic outcomes at 1 year of loading. J Clin Periodontol. 2015 Nov;42(11):1042-51. https://doi.org/10.1111/jcpe.12465 
35. Thoma DS, Haas R, Tutak M, Garcia A, Schincaglia GP, Hämmerle $\mathrm{CH}$. Randomized controlled multicentre study comparing short dental implants $(6 \mathrm{~mm})$ versus longer dental implants (11-15 mm) in combination with sinus floor elevation procedures. Part 1: demographics and patient-reported outcomes at 1 year of loading. J Clin Periodontol. 2015 Jan;42(1):72-80. https://doi.org/10.1111/icpe.12323

36. Felice P, Pistilli R, Piattelli M, Soardi E, Corvino V, Esposito $M$. Posterior atrophic jaws rehabilitated with prostheses supported by $5 \times 5 \mathrm{~mm}$ implants with a novel nanostructured calcium-incorporated titanium surface or by longer implants in augmented bone. Preliminary results from a randomised controlled trial. Eur J Oral Implantol. 2012;5(2):149-61.

37. Felice P, Checchi V, Pistilli R, Scarano A, Pellegrino G, Esposito M. Bone augmentation versus $5-\mathrm{mm}$ dental implants in posterior atrophic jaws. Four-month post-loading results from a randomised controlled clinical trial. Eur J Oral Implantol. 2009;2(4):267-81.

38. Esposito M, Cannizzaro G, Soardi E, Pistilli R, Piattelli M, Corvino $\mathrm{V}$ et al. Posterior atrophic jaws rehabilitated with prostheses supported by $6 \mathrm{~mm}$-long, $4 \mathrm{~mm}$-wide implants or by longer implants in augmented bone. Preliminary results from a pilot randomised controlled trial. Eur J Oral Implantol. 2012;5(1):19-33.

39. Shi JY, Gu YX, Qiao SC, Zhuang LF, Zhang XM, Lai HC. Clinical evaluation of short 6-mm implants alone, short 8-mm implants combined with osteotome sinus floor elevation and standard 10-mm implants combined with osteotome sinus floor elevation in posterior maxillae: study protocol for a randomized controlled trial. Trials. 2015 Jul;16(1):324. https://doi.org/10.1186/s13063-015-0853-4

40. French D, Nadji N, Shariati B, Hatzimanolakis P, Larjava $H$. Survival and success rates of dental implants placed using osteotome sinus floor elevation without added bone grafting: a retrospective study with a follow-up of up to 10 years. Int J Periodontics Restorative Dent. 2016;36 Suppl:s89-97. https://doi.org/10.11607/prd.2191

41. Nedir R, Nurdin N, Abi Najm S, El Hage M, Bischof M. Short implants placed with or without grafting into atrophic sinuses: the 5 -year results of a prospective randomized controlled study. Clin Oral Implants Res. 2017 Jul;28(7):877-886. https:doi.org/10.1111/clr.12893

42. Taschieri S, Corbella S, Del Fabbro M. Miniinvasive osteotome sinus floor elevation in partially edentulous atrophic maxilla using reduced length dental implants: interim results of a prospective study. Clin Implant Dent Relat Res. 2014 Apr;16(2):185-93. https://doi.org/10.1111/j.1708-8208.2012.00483.x

43. Pieri F, Aldini NN, Fini M, Marchetti C, Corinaldesi G. Retraction. Rehabilitation of the atrophic posterior maxilla using short implants or sinus augmentation with simultaneous standard-length implant placement: a 3-year randomized clinical trial. Clin Implant Dent Relat Res. 2012 Dec;14(6):924. https://doi.org/10.1111/cid.12029
44. Thoma DS, Zeltner M, Hüsler J, Hämmerle CH, Jung RE. EAO Supplement Working Group 4 - EAO CC 2015 Short implants versus sinus lifting with longer implants to restore the posterior maxilla: a systematic review. Clin Oral Implants Res. 2015 Sep;26 Suppl 11:154-69. https://doi.org/10.1111/clr.12615

45. Telleman G, Raghoebar GM, Vissink A, Hartog L, Huddleston Slater JJ, Meijer HJ. A systematic review of the prognosis of short $(<10 \mathrm{~mm}$ ) dental implants placed in the partially edentulous patient. J Clin Periodontol. 2011 Jul;38(7):667-76. https://doi.org/10.1111/j.1600-051X.2011.01736.x

46. Mezzomo LA, Miller R, Triches D, Alonso F, Shinkai RS. Meta-analysis of single crowns supported by short $(<10 \mathrm{~mm})$ implants in the posterior region. J Clin Periodontol. 2014 Feb;41(2):191-213. https://doi.org/10.1111/jcpe.12180

47. Goiato MC, Santos DM, Santiago Junior JF, Moreno A, Pellizzer EP. Longevity of dental implants in type IV bone: a systematic review. Int J Oral Maxillofac Surg. 2014 Sep;43(9):1108-16. https://doi.org/10.1016/i.ijom.2014.02.016

48. Pommer B, Frantal S, Willer J, Posch M, Watzek $G$, Tepper G. Impact of dental implant length on early failure rates: a meta-analysis of observational studies. J Clin Periodontol. 2011 Sep;38(9):856-63. https://doi.org/10.1111/j.1600-051X.2011.01750.x

49. Kotsovilis S, Fourmousis I, Karoussis IK, Bamia C. A systematic review and meta-analysis on the effect of implant length on the survival of rough-surface dental implants. J Periodontol. 2009 Nov;80(11):1700-18. https://doi.org/10.1902/jop.2009.090107

50. Seker E, Ulusoy M, Ozan O, Doğan DO, Seker BK. Biomechanical effects of different fixed partial denture designs planned on bicortically anchored short, graftsupported long, or 45-degree-inclined long implants in the posterior maxilla: a three-dimensional finite element analysis. Int J Oral Maxillofac Implants. 2014 Jan-Feb;29(1):e1-9. https://doi.org/10.11607/jomi.3264

51. Pellizzer EP, de Mello CC, Santiago Junior JF, Batista VES, Almeida DAF, Verri FR. Analysis of the biomechanical behavior of short implants: the photoelasticity method. Mater Sci Eng C. 2015 Oct;55:187-92. https://doi.org/10.1016/i.msec.2015.05.024

52. Ortega-Oller I, Suárez F, Galindo-Moreno P, TorrecillasMartínez L, Monje A, Catena A et al. The influence of implant diameter on its survival: a meta-analysis based on prospective clinical trials. J Periodontol. 2014 Apr;85(4):569-80. https://doi.org/10.1902/jop.2013.130043

53. Coelho Goiato M, Pesqueira AA, Santos DM, Haddad MF, Moreno A. Photoelastic stress analysis in prosthetic implants of different diameters: mini, narrow, standard or wide. J Clin Diagn Res. 2014 Sep;8(9):ZC86-90. https://doi.org/10.7860/JCDR/2014/8489.4902

54. Javed F, Romanos GE. Role of implant diameter on longterm survival of dental implants placed in posterior maxilla: a systematic review. Clin Oral Investig. 2015 Jan;19(1):1-10. https://doi.org/10.1007/s00784-014-1333-z 
55. Peñarrocha-Oltra $D$, Covani $U$, Peñarrocha $M$, Peñarrocha-Diago M. Immediate versus conventional loading with fixed full-arch prostheses in mandibles with failing dentition: a prospective controlled study. Int J Oral Maxillofac Implants. 2015 Mar-Apr;30(2):427-34. https://doi.org/10.11607/jomi.3534

56. van Kesteren CJ, Schoolfield J, West J, Oates T. A prospective randomized clinical study of changes in soft tissue position following immediate and delayed implant placement. Int J Oral Maxillofac Implants. 2010 May-Jun;25(3):562-70.

57. Herekar M, Sethi M, Mulani S, Fernandes A, Kulkarni $\mathrm{H}$. Influence of platform switching on periimplant bone loss: a systematic review and metaanalysis. Implant Dent. 2014 Aug;23(4):439-50. https://doi.org/10.1097/ID.0000000000000080

58. Guljé F, Abrahamsson I, Chen S, Stanford C, Zadeh H, Palmer R. Implants of $6 \mathrm{~mm}$ vs. $11 \mathrm{~mm}$ lengths in the posterior maxilla and mandible: a 1-year multicenter randomized controlled trial. Clin Oral Implants Res. 2013 Dec;24(12):1325-31. https://doi.org/10.1111/clr.12001

59. Huwiler MA, Pjetursson BE, Bosshardt DD, Salvi GE, Lang NP. Resonance frequency analysis in relation to jawbone characteristics and during early healing of implant installation. Clin Oral Implants Res. 2007 Jun;18(3):275-80. https://doi.org/10.1111/j.1600-0501.2007.01336.x

60. Sollazzo V, Pezzetti F, Scarano A, Piattelli A, Bignozzi CA, Massari $L$ et al. Zirconium oxide coating improves implant osseointegration in vivo. Dent Mater. 2008 Mar;24(3):357-61. https://doi.org/10.1016/i.dental.2007.06.003

61. Luongo G, Lenzi C, Raes F, Eccellente T, Ortolani M, Mangano $C$. Immediate functional loading of single implants: a 1 -year interim report of a 5-year prospective multicentre study. Eur J Oral Implantol. 2014;7(2):187-99.

62. Renouard F, Nisand D. Short implants in the severely resorbed maxilla: a 2-year retrospective clinical study. Clin Implant Dent Relat Res. 2005;7(s1 Suppl 1):S104-10. https://doi.org/10.1111/i.1708-8208.2005.tb00082.x

63. Chrcanovic BR, Albrektsson T, Wennerberg A. Reasons for failures of oral implants. J Oral Rehabil. 2014 Jun;41(6):44376. https://doi.org/10.1111/joor.12157

64. Nedir R, Bischof M, Briaux JM, Beyer S, SzmuklerMoncler S, Bernard JP. A 7-year life table analysis from a prospective study on ITI implants with special emphasis on the use of short implants. Results from a private practice. Clin Oral Implants Res. 2004 Apr;15(2):150-7. https://doi.org/10.1111/j.1600-0501.2004.00978.x
65. Doornewaard R, Christiaens V, De Bruyn H, Jacobsson $M$, Cosyn J, Vervaeke $S$ et al. Long-term effect of surface roughness and patients' factors on crestal bone loss at dental implants: a systematic review and meta-analysis. Clin Implant Dent Relat Res. 2017 Apr;19(2):372-99. https://doi.org/10.1111/cid.12457

66. Sheridan RA, Decker AM, Plonka AB, Wang HL. The role of occlusion in implant therapy: a comprehensive updated review. Implant Dent. 2016 Dec;25(6):829-38. https://doi.org/10.1097/ID.0000000000000488

67. Lemos CA, Batista VES, Almeida DA, Santiago Júnior $J F$, Verri FR, Pellizzer EP. Evaluation of cement-retained versus screw-retained implant-supported restorations for marginal bone loss: A systematic review and metaanalysis. J Prosthet Dent. 2016 Apr;115(4):419-27. https://doi.org/10.1016/i.prosdent.2015.08.026

68. Clementini M, Rossetti PH, Penarrocha D, Micarelli C, Bonachela WC, Canullo L. Systemic risk factors for periimplant bone loss: a systematic review and meta-analysis. Int J Oral Maxillofac Surg. 2014 Mar;43(3):323-34. https://doi.org/10.1016/i.ijom.2013.11.012

69. Lee SA, Lee CT, Fu MM, Elmisalati W, Chuang SK. Systematic review and meta-analysis of randomized controlled trials for the management of limited vertical height in the posterior region: short implants ( 5 to $8 \mathrm{~mm}$ ) vs longer implants $(>8 \mathrm{~mm}$ ) in vertically augmented sites. Int J Oral Maxillofac Implants. 2014 Sep-Oct;29(5):1085-97. https://doi.org/10.11607/jomi.3504

70. Esposito M, Grusovin MG, Felice P, Karatzopoulos G, Worthington HV, Coulthard P. Interventions for replacing missing teeth: horizontal and vertical bone augmentation techniques for dental implant treatment. Cochrane Database Syst Rev. 2009 Oct;7(4):CD003607. PMID:19821311

71. Quaranta A, Piemontese M, Rappelli G, Sammartino G, Procaccini M. Technical and biological complications related to crown to implant ratio: a systematic review. Implant Dent. 2014 Apr;23(2):180-7. https://doi.org/10.1097/ID.0000000000000026

72. Urdaneta RA, Rodriguez S, McNeil DC, Weed M, Chuang SK. The effect of increased crown-to-implant ratio on single-tooth locking-taper implants. Int J Oral Maxillofac Implants. 2010 Jul-Aug;25(4):729-43.

73. Verri FR, Batista VE, Santiago Junior JF, Almeida DA, Pellizzer EP. Effect of crown-to-implant ratio on peri-implant stress: a finite element analysis. Mater Sci Eng C. 2014 Dec;45:234-40. https://doi.org/10.1016/i.msec.2014.09.005 